\title{
The use of high technology in STEM education
}

\section{Vasudevan Lakshminarayanan, Annette McBride}

Vasudevan Lakshminarayanan, Annette C. McBride, "The use of high technology in STEM education," Proc. SPIE 9793, Education and Training in Optics and Photonics: ETOP 2015, $97930 \mathrm{C}$ (8 October 2015); doi: 10.1117/12.2223062

SDIE Event: Education and Training in Optics and Photonics: ETOP 2015, 2015, Bordeaux, France 


\title{
The Use of High Technology in STEM Education
}

\author{
Vasudevan Lakshminarayanan*a , Annette C. McBride ${ }^{\mathrm{b}}$ \\ ${ }^{a}$ School of Optometry and Vision Science, University of Waterloo, Waterloo, ON, Canada N2L3G1 \\ and \\ Department of Physics, University of Michigan, Ann Arbor, MI, USA 48109 \\ b3509 Edgewood Drive, Ann Arbor, MI, USA 48104
}

\begin{abstract}
There has been a huge increase in the use of high technology in education. In this paper we discuss some aspects of technology that have major applications in STEM education, namely, (a) virtual reality systems, (b) personal electronic response systems aka "clickers", (c) flipped classrooms, (d) mobile learning "m-Learning", (e) massive open online courses "MOOCS", (f) internet-of-things and (g) cloud computing.
\end{abstract}

Keywords: STEM education, information technology, high technology, education

\section{INTRODUCTION}

It has been estimated that the number of people who are enrolled in higher education is greater than 165 million ${ }^{1}$. This number is estimated to increase to about 262 million in about a decade from now ${ }^{2}$. Nearly all of this growth will be in the developing world, with more than half in China and India alone. How do we deal with these huge numbers? According to UNESCO, accommodating the additional students would require that more than four major universities $(30,000+$ enrollment) would have to open every week for the next fifteen years (this is based on 2011 data). This is not happening due to a number of reasons, including of course, the cost. Even in China, which has made a major commitment to higher education, the number of college-eligible students is growing at a rate faster than the number of available faculty or facilities.

What is the situation in primary and middle schools? According to the World Bank data ${ }^{3}$, only about $73 \%$ of eligible children are enrolled in secondary and primary schools. Only $32 \%$ are enrolled in tertiary school. This works out to approximately 60 million children out of schools (primary). These data also show that this situation occurs primarily in developing nations.

There are two major problems: one is the sheer number of students who need to be educated; the second is how do we teach effectively ? $^{4}$. In particular, as scientist-educators, we need to make our teaching more relevant and effective for a much larger audience than simply science and engineering students. This is simply because as a species we face global scale problems (climate change, pandemics, energy, aging population, genetic engineering,...) whose solutions depend upon science. Leaders (politicians) need to be science literate and citizens of every country can help guide their own destinies by understanding the science behind issues that face them individually. A second reason is that modern economics and the GDP (and hence living standards) depend upon science and technology and students need a better technical understanding and problem solving skills. Therefore, there is a need to improve teaching in STEM areas not just for science and engineering students but for all.

Classroom education today has not changed much since the nineteenth centtury. Schools are primarily modeled on factories of that era. Students in general are grouped together based on age and are basically on a virtual assembly line conveyer belt. Instruction ("teaching") is thrown at the students in the assembly line, and they pick up what ever they can as they move on toward graduation. Graduation often depends upon completion of a series of exams which normally do not take into account individual characteristics, talents and creativity. Nor is group/peer interaction generally allowed. Instruction is not individualized or customized. In fact, one can argue that the more people we have to educate, the less individualized is the instruction.

*vengu@uwaterloo.ca; phone 1519 888-4567 ext.38167; https:/uwaterloo.ca/optometry-vision-science/people-profiles/vasudevanlakshminarayanan

Education and Training in Optics and Photonics: ETOP 2015, edited by Eric Cormier, Laurent Sarger Proc. of SPIE Vol. 9793, 97930C · C 2015 SPIE, IEEE, OSA, ICO · doi: 10.1117/12.2223062 
Consider physics education in college. Traditional physics teaching is hierarcical where the professor lectures and evaluates students through homework, problem sets and exams. The professor lectures on subtopics such as optics or mechanics, usually expanding on that topic or more often simply regurgitating the textbook. Problem sets involve plugging numbers into problems which are similarly structured, essentially 'reproducing' what was presented in the textbook as worked examples. This routine is intended to equip the physics student with problem solving skills ${ }^{5,6}$. The laboratory exercises are usually analogous to a cookbook and are highly choreographed - these are designed to teach students to design, execute and analyze data. All of this makes for a very passive classroom experience. Such a learning process does not encourage creativity nor does it highlight the intellectual pleasures of physics. This rote learning experience can discourage students from continuing their education in physics (or for that matter in the sciences) ${ }^{7,8}$. The effectiveness of such teaching has been studied by a number of physics education researchers ${ }^{9}$. Is there a better way to teach STEM that avoids the problems of traditional teaching? There are numerous studies (especially by physics education researchers) that say the answer is unequivocally yes. ${ }^{10-15}$ These teaching methods include (1) basing the pedagogical technique on education research and data rather than on tradition and anecdotes, (2) dissemination and copying of previous results and (3) adapting new technological tools to enhance student learning. We are going to concentrate on new technological teaching tools in this paper. We believe that optimally using new technological tools will enhance student learning, allow the instructor to tailor their classes to suit the individual student and will also be useful for dealing with large numbers of students. A caveat is that we will be dealing only with processes and methods that are enabled by information technology.

\section{USE OF NEW TECHNOLOGY}

Technology can make it easier to incorporate principles established by education research. For example, student faculty e-mail (or for that matter Facebook or Twitter or other social media) can help faculty understand and guide student thinking. Online surveys can be used also. The use of computers as an educational aid goes back to the early $1950 \mathrm{~s}^{16}$. Since the advent of the personal computer in the late seventies, they have become a recognized delivery system for many forms of education. The introduction of the smart phone and iPad like mobile devices have further enhanced means of delivering education. However, it should be emphasized that student perspectives should be taken into account in using such technologies especially if one wants to increase the numbers of traditionally under-represented minorities and women in the sciences. ${ }^{17}$ In this article, we want to discuss the following four aids to education: (a) virtual reality systems, (b) personal electronic response systems aka "clickers", (c) flipped classrooms, (d) mobile learning "mLearning", (e) massive open online courses "MOOCs", (f) internet-of-things and (g) cloud computing.

\section{a.Virtual Reality}

Virtual reality (VR; also known as virtual environment) uses computer generated imagery and human computer interfaces to create the effect of a three dimensional world where the user interacts directly with the virtual object using a number of peripheral devices. The key in VR is that it is $3 \mathrm{D}$, interactive and most importantly it creates the effect of interacting with things, not with pictures. As Bryson ${ }^{18}$ states, "it is an effect, not an illusion". Perhaps because of the computer and game industry, and associated open-source and game engine toolkits, there is interest in using such VR, immersive technologies for education and for engaging the students. Students can take advantage of the affordances of simulated environments, exploring a scenario's dimensions and pitfalls as they learn. This motivational iterative process, the learning-while-doing, is very important ${ }^{19,20}$. The ability to work "hands-on" and view objects from multiple viewpoints made possible by VR can deepen learning and recall for a student because the student is experiencing the construction of new knowledge ${ }^{21}$. This type of experiential learning promotes the construction of knowledge by the student, where learning is characterized as a series of cognitive restructurings. The learner's conceptual framework undergoes structural modifications or revisions based upon new experiences, information, or concepts the learner encounters. This process would allow the learners' cognition to move from representational learning to conceptual learning, a process enabled by VR. If this process does not occur, then the learner stays in the stage of representational learning, i.e., rote memorization. As pointed out in the Introduction, rote memorization as an educational strategy is not a good option since students' success may depend upon their ability to envision and manipulate abstract multidimensional information spaces ${ }^{22}$. Studies show that a virtual environment can "stimulate learning and comprehension, because it provides a tight coupling between symbolic and experiential information" ${ }^{23}$. Chee ${ }^{24}$ states that 
experience is necessary for optimal learning, and that physics students have little "feel" and "understanding of the qualitative dimensions of the phenomena they study". VR can be used to provide "a foundation for students' conceptual and higher order learning". A good example of a successful VR system in Optics is the MaxwellWorld system ${ }^{25}$. This system allows students to explore electrostatic forces and fields, learn about the concept of electric potential, and discover the nature of electric flux. This is partly because students cannot draw analogies to personal experiences that provide metaphors. In this VR system, students build 3D electric fields and explore forces and energy by directly manipulating 3D representations of test charges, field lines, equipotential surfaces, flux surfaces, etc. These authors also report that students had a greater understanding of the distribution of forces in an electric field, as well as representations such as test charge traces and field lines. They also state that the three-dimensional nature of VR aids with learning and that the virtual reality experience is more motivating for students than a comparable 2-D microworld.

The first use of VR in training was done by the United States Air Force using head mounted displays and simulators back in the 1950s. Pantelidas ${ }^{26}$ provides a huge bibliography of articles on the use of VR in education and training. So, when does one use a VR system for teaching and when not to use VR systems? This issue is addressed by Pantelidas ${ }^{27}$ and issues associated with design and development of VR for education and the challenges faced by educators who want to incorporate VR in their teaching can by found in reference 28. Chen ${ }^{29}$ makes an important point that "although VR is recognized as an impressive learning tool, there are still many issues that need further investigation including, identifying the appropriate theories and/or models to guide its design and development, investigating how its attributes are able to support learning, finding out whether its use can improve the intended performance and understanding, and investigating ways to reach more effective learning when using this technology, and investigating its impact on learners with different aptitudes".

\section{b. Personal electronic response systems "Clickers"}

Many instructors currently use classroom technology that allows students to respond and interact via small, hand-held, remote keypads. This technology, are commonly called "clickers" or "key-pads" ("handsets" or "zappers" in the United Kingdom) and are small hand held transmitters. Students can use their clickers to transmit their answers by pressing the buttons. Clickers usually have a 10-digit numeric keypad and often some accessory (e.g., power switch, a send button, or function keys that permit text entry) and are "two-way," meaning that the clicker not only sends a signal but also indicates whether it was received. Although early clickers were often connected to the rest of the system by wiring, modern systems are wireless and use either infrared (IR) or, more recently, radiofrequency (RF) signals. In all systems, each clicker unit has a unique signal so that the answer from each individual student can be identified and recorded. When polling is complete, answers from the entire class are displayed on the projection screen, usually in the form of a histogram, although some systems offer more sophisticated options. The feature of an clicker system is that it allows this mass of student answers to be rapidly collected, tabulated, and displayed is the coupling of a proprietary receiver unit with an ordinary classroom computer and projection system. Such systems of clickers, receiver, and software have various names such as classroom response system, personal response system, classroom communication system, group response system, audience response system, electronic voting system, audience paced feedback system, and classroom network audience response system. Software included with clicker systems not only controls display settings and data collection during class but also helps the instructor format questions (usually as PowerPoint slides) and grade student responses. Grading tools in the software typically allow the instructor to specify which answer or answers will be treated as correct. These tools also permit different point values to be given for correct versus incorrect answers. Typical systems can export or even upload student scores to classroom management systems such as Blackboard. A comparison of these clicker systems can be found elsewhere ${ }^{30,31}$. Clickers have been used extensively in physics courses (amongst others) ${ }^{32-38}$. A bibliography of clicker use in various courses has been compiled by the Center for Teaching at Vanderbilt University (Nashville, TN) ${ }^{39}$.

Most studies have found clickers to be a powerful, flexible and effective tool especially in large classes. Because clickers can effectively engage students, they enhance students' active learning, participation, and enjoyment of classes. When used during lectures, clickers have either neutral or positive effects and a more strongly positive effect on learning outcomes when combined with peer or cooperative learning. Another interesting outcome ${ }^{40}$ as reported by Professor Bill Reay of Ohio State University is that he and his group found that in an undergraduate course dealing with electromagnetism (about 700 students), there was roughly a $10 \%$ improvement in student performance when clickers were used. What is noteworthy is that clickers seemed to help female students more than male students. It is speculated that the anonymity of the devices may offer an advantage. In surveys, nearly all the students -- male and female -- said they liked having the ability to keep their answers private. Students can easily hold the clicker in one hand and block 
their neighbor's view. The clickers increase attendance and retention and can be used to promote student accountability. They simulate a one-to-many dialogue and make it easier for both instructors and students to receive prompt feedback. There are a number of resources for using clickers ${ }^{41}$; a a set of guidelines for writing good questions and a list of bestpractice tips have been culled from the literature and experienced users is given in reference ${ }^{42}$.

One of the major drawbacks of clicker systems is the cost associated with acquiring them. The costs vary depending upon the system. In addition students have to buy an individual clicker. However there are some free alternatives that can be used - these include for example, Socrative (www.socrative.com), soapbox (http://www.gosoapbox.com/) and Poll Everywhere (http://www.polleverywhere.com/). These systems use either the student's cell phone, computer/laptop or text messaging.

\section{c. Flipped Classrooms}

The flipped (or inverted) classroom nothing but a model of learning that rearranges how time is spent both in and out of class to shift the ownership of learning from the educators to the students. The simplest definition of the flipped classroom is: "Inverting the classroom means that events that have traditionally taken place inside the classroom now take place outside the classroom and vice versa"43 In this paradigm class time is devoted to higher cognitive, more active, project-based and/or problem based learning where students work together to solve local or global challenges or other real-world applications - to gain a deeper understanding of the subject. Rather than the instructor using class time to lecture, that work is done by the student after (or before) class. This takes many forms: watching video lectures, listening to podcasts, perusing enhanced e-book content, or collaborating with peers in online communities ${ }^{44}$. Students can access online tools and resources whenever (and where ever) they need them. Hence, faculty can devote more time to interacting with each individual. After class, students manage the content they use, the pace and style of learning, and the ways in which they demonstrate their knowledge; the instructor adapts instructional and collaborative approaches to suit their learning needs. The flipped classroom model is part of a larger pedagogical movement that overlaps with blended learning, inquiry-based learning, and other instructional approaches and tools that are meant to be flexible, active, and more engaging for students.

The first documented instance of the flipped classroom comes from a high school in Colorado where chemistry was taught in this fashion ${ }^{45}$. Flipped classrooms are seen being well suited for higher education because the rearranging of class time gives students in large introductory lecture courses more opportunity to engage and interact with their peers. Instructors also make more efficient use of their time by focusing on content that is especially challenging for students. Often clickers (vide supra) in large seminars are often paired with this method in order to help understand students' comprehension of material and customize discussions accordingly. According to a survey conducted in 2013 by the Center for Digital Education ${ }^{46}$, found that in the USA $29 \%$ of faculty were using the flipped classroom and another $27 \%$ said they planned to use it within a year. The survey also showed that among those employing this paradigm, 57\% agree that their flipped classroom is "extremely successful" or "successful", citing key student benefits of "improved mastery of information" and "improved retention of information", at 81 percent and 80 percent of responses respectively.

In addition to video lectures, other technologies such as e-books with collaborative annotation and discussion software can enable instructors to be in sync with their students' learning patterns. By reviewing the comments and questions that students pose online, instructors can better prepare for class and address particularly challenging ideas and concepts. Therefore, learning environment transforms into a dynamic and more social space where students can participate in critiques or work through problems in teams. In a traditional classroom this often necessitates a physical rearrangement of the space by moving chairs, tables, etc. While there is not much literature on the effectiveness of the flipped classroom model ${ }^{47}$ as compared with traditional teaching methods, there are several experiments currently underway. A very good survey of the research is given by Bishop and Verleger ${ }^{48}$. A meta-analysis of current research on flipped learning can be found in reference 49 .

What are the challenges in implementing a flipped classroom? There are four major problems. They include (1) course redesign, (2) faculty workload, (3) student buy-in and (4) student evaluations. Perhaps the most common difficulty that faculty face is simply the extra time and effort required to redesign an existing course. To flip a course requires additional upfront work (with consequent large time investment) and a willingness to experiment with different methods. One can alleviate the pressure of redesigning a course by not working alone. Instructors often find it helpful to work with one or more colleagues to flip a course. Co-teaching is often an advantage in that instructors can make the videos together, switch off making the lessons for each unit, or have one make the videos and the other create classroom activities, etc. It is also important that the faculty member be trained to introduce/use flipped classroom methods. 
Another important obstacle to implementing flipped classrooms is student buy-in. While some students struggle with the traditional lecture method, others have become so used to that style that they have a hard time adjusting to something different. The active learning tasks that are characteristic of a flipped course require students to put in more effort during class (and also outside of class) and to stay current with the pace of the course. Student evaluations of flipped courses in higher education have varied, with some favoring the hands-on, peer-instruction activities in class and others finding it difficult to follow. Different students have different styles of learning and some will tend to favor the flipped model while others will not. As students and faculty become more experienced with the approach, it is likely that opposition will decrease. Also, it should be noted that flipped classrooms may not be for every teacher in every type of class, so the first thing is to determine its applicability to his or her specific course.

\section{d. Mobile learning (m-Learning)}

M-learning or mobile learning is defined as "learning across multiple contexts, through social and content interactions, using personal electronic devices." ${ }^{, 50}$. A form of electronic learning distance education, m-learners can use mobile device educational technology in many locations at their time convenience.

Mobile devices such as smartphones, iPads, netbooks and tablets are widely used and play a major role in how people communicate and access information. As a result there has been considerable research on novel applications in mobile learning over the last decade $e^{51,52}$ taking advantage of user and device mobility for facilitating learning across multiple contexts, involving different locations including classrooms, tasks and modes of interaction among users. Mobile devices have been used in classrooms for note taking and presentations, as formative assessment tools ${ }^{53}$, for games, participatory simulations ${ }^{54}$, and problem-solving activities ${ }^{55}$. They can be used in collaborative learning activities.

The Educause Center for Applied Research $[\mathrm{ECAR}]^{56}$ survey on Mobile IT in higher education states that students are driving the adoption of mobile computing devices, such as cellphones, smartphones, and tablet computers, in higher education, and $67 \%$ of surveyed students believe mobile devices are important to their academic success and computing devices on college campuses has the potential to create new options for higher education students and the exploration of mobility and social media as an instructional strategy. A recent major study reports that mobile computing devices and the use of social media created opportunities for interaction, provided opportunities for collaboration, as well as allowed students to engage in content creation and communication using social media and Web 2.0 tools with the assistance of constant connectivity ${ }^{57}$. This study supports the statement that mobile learning offers much more educational potential than simply accessing resources. ${ }^{57,58}$ It has been noted that "education in the mobile age does not replace formal education, ...; rather it offers a way to extend the support of learning outside the classroom, to the conversations and interactions of everyday life" ${ }^{\prime 59}$. Various issues dealing with m-learning are discussed in a recent book ${ }^{60}$. For $\mathrm{m}$ Learning even social networking systems such as Twitter have been used to enable effective interaction and engagement in large classroom ${ }^{61}$. Various technologies for facilitating the implementation of collaborative learning environments in the classroom supported by one-to-one mobile computing have been developed (see for example reference 62). Because the technology is moving at a faster pace than research, mobile learning research is still in the relatively early stages ${ }^{63}$ with mobile phones and PDAs the most studied devices. ${ }^{64}$ The use of other mobile technologies, namely tablets, netbooks, and e-book readers on learning are areas that need further study.

\section{e. Massive Open Online Courses (MOOCs)}

Over the past few years, people in higher education have analyzed the major changes that must occur to educate large numbers of students and with lowered costs. A shift from simple accumulation of knowledge to the acquisition of a variety of cognitive and non-cognitive skills was also considered. A simple solution is of course online learning combined with technology. MOOCs (Massive Open Online Courses) are thought to be a solution to the problem. MOOCs are thought to be a way to democratize education. A MOOC is an online course aimed at large-scale participation and open (free) access via the internet. They are similar to university courses, but do not tend to offer academic credit. A number of web-based platforms (providers) supported by top universities and colleges offer MOOCs in a wide range of subjects. A number of issues ranging from instructional design to legal issues are discussed in recent books $^{65,-67}$.

The history of MOOCs can be traced back to correspondence courses offered by many Universities and distance learning programs. It has been suggested that MOOCS is really history repeating itself but with a different delivery model ${ }^{68}$. With advances in digital technology educators took advantage of floppy disks, CD-ROMS, and user friendly software to improve distance learning. Even regular pedagogy - formal textbooks and written assignments - were influenced by digital technologies such as Blackboard, leading physical classrooms to integrate knowledge with hardware and software 
interfaces. The first MOOC (as we now recognize it) was called 'Connectivism and Connective Knowledge/2008' (CCK8), created by Stephen Downes and George Siemens and was built off a for-credit course at the University of Manitoba. This was the first class designed behind the acronym of 'MOOC' and used many different platforms to engage students with the topic, including Facebook groups, Wiki pages, blogs, forums and other resources.

Around 2,200 people signed up for CCK08, and 170 of them created their own blogs. The course was free and open, which meant that anyone could join, modify or remix the content without paying (although a paid, certified option was offered). The University of Illinois offered a not-for-credit course with 2,700 participants in 2011. In 2012 Stanford Professors Sebastian Thrun and Peter Norvig offered a course called "Introduction to Artificial Intelligence" for free online. More than 160,000 students in 190 countries signed up, and for the first time, an open online course was truly 'massive'. As a result,Thrun and Norvig in 2012 to build a new business model for online knowledge, Udacity (www.udacity.com) $)^{69}$. Udacity (www.udacity.com) is a for-profit company providing learning options primarily in computer science and math. In 2012, Harvard and MIT launched the non-profit, edX, (www.edx.org) which the University of California at Berkeley also joined. EdX made it clear that it's agenda was to explore innovative ways to improve classroom education, not to replace $\mathrm{it}^{70}$. Also in 2012, the for-profit company Coursera (www.coursera.org) was founded. Coursera partners with many different universities. In 2013, the the Open University in the UK built its MOOC platform, Futurelearn (www.futurelearn.com), which features universities from the United Kingdom. And there are many other independent MOOC initiatives, including Open2Study (www.open2study.com) in Australia and iversity(https://iversity.org/) in Germany. A good online directory of MOOCS providers and courses can be found at http://www.moocs.co/ which not only lists higher education but also K-12, and Corporate MOOCs. Another good source to search for providers and courses is https://www.mooc-list.com/.

In 2014, the number of universities offering MOOCs is over 400 with a doubling of the number of cumulative courses offered, to over 2400. In fact 22 of the top 25 US universities in US News World Report rankings offer courses online for free. In terms of numbers, Coursera offered about 800, while EdX offered about 400 MOOCs. Their enrollment numbers were about 10.5 million and 3 million respectively. MiriadaX (www.miriadax.net/home) became the first nonU.S. MOOC provider to cross 1 million registered users, tapping into the large Spanish-speaking market worldwide. MiriadaX is a consortium of over 30 Spanish Universities. The UK provider FutureLearn had about $800 \mathrm{~K}$ registered users. Up-to date numbers of courses and information can be found at : https://www.class-central.com/providers .

The top three course areas are in the humanities, computer science and programming and business and management. There has been some debate whether MOOCs can be as useful for teaching humanities and non-technical subjects as it is for computer science and math ${ }^{71}$. This is an open question. The number of "pure" science courses accounted for only about $12 \%$ and engineering (non-computer science) about $5 \%$ of the total number of courses offered. A quick search using the term "optics" on Mooc-list.com came out with a listing of 69 courses and included courses in electricity and magnetism $^{72}$ (and at all levels). The top twenty search terms account for about $12 \%$ of the total number of courses and are: python, healthcare, java, finance, android, English, statistics, marketing, music, writing, psychology, accounting, design, Spanish, programming, law, photography, big data, history. Also in 2014 there were some major changes namely some MOOC providers started their own "degrees/credentials": Udacity's Nanodegrees, Coursera's

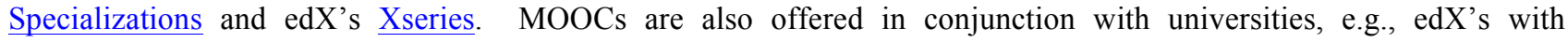
professional education programs and NovoEd's with Stanford Business School. A few universities experimented with directly offering credits for MOOCs, e.g., University of Oklahoma, and the Pennsylvania State University. Detailed discussions of these can be found in reference 73 .

How many students enroll in a MOOC and how many finish the course? This is a very interesting question. A study ${ }^{74}$ published in 2013, looked at enrollment in 279 courses taught by Coursera, Udacity and edX found an average number of 43,000 students per course. However, the number who complete the course was less than $7 \%$. Jordan ${ }^{75}$ points out that a typical MOOC has about 20,000 students and a completion rate of less than $10 \%$. MOOCs are undoubtedly huge and have considerable disruptive potential. There are many questions including will MOOCs expand access to higher education to those who do not already have the means to obtain it (cost issue) and will they help people gain skills for a high quality job or desire to learn? There is much publicity about the potential of MOOCs. For example, the columnist Tom Friedman of the New York Times has written ${ }^{76}$ "Nothing has more potential to lift more people out of poverty... Nothing has more potential to unlock a billion more brains to solve the world's biggest problems...than the massive open online course." . A recent paper looked into this issue in detail ${ }^{77}$. The authors of this study conducted an an online survey of students enrolled in at least one of the University of Pennsylvania's 32 MOOCs offed on the Coursera platform. They found that the student population tended to be young, well educated, and employed, with a 
majority from developed countries. There were significantly more males than females taking MOOCs, especially in developing countries. Students' main reasons for taking a MOOC were to advancing in their current job and satisfying curiosity. The individuals the MOOC revolution is supposed to help the most-those without access to higher education in developing countries - were underrepresented among the early adopters of MOOCs. MOOCs bring a new perspective to traditional distance education but are still in the early stages. At a time when higher education is being criticized for low productivity, increasing costs, and inefficient use of technology ${ }^{78}$, MOOCs provide a viable alternative in that they offer high productivity, free (or low cost), and utilization of high technology. The major problem is to find the right way to improve access and affordability while at the same time maintain academic rigor and continued student success. There are many challenges both in terms of what MOOCs mean to the traditional educational institution as well as to how information is conveyed with rigorous individual student-teacher interaction.

The Khan academy (https://www.khanacademy.org/) is a good example of an internet based, MOOC educational tool. This organization produces micro - lectures in the form of You Tube videos. There are over 6500 videos on various topics ranging from math and computer science, programming, physics, biology, chemistry to American civics and history, health care and economics. The web site and resources have been translated into dozens of languages. In addition to lectures, the Khan Academy website has practice exercises and tools for educators. All resources are available for free to anyone around the world. In addition, it has a personalized learning algorithm to help people track what they have learned and recommend what they can do next. This is an example of an adaptive web-based exercise system that generates problems for students based on skill and performance.

\section{f. Internet-of-things}

When TCP/IPv6 launched in 2006, the new network expanded the capabilities of the Internet and enabled objects, sensors, and devices to be addressable and communicate across the Internet. ${ }^{79}$ The Internet of Things (IoT) is a network of connected physical real objects that link the physical world through the web. The physical objects have embedded computational and networking capabilities which can communicate and interact with one another, with other computing devicesas well as with users on the Internet. With the advent and growth of the IoT, homes, workplaces, and educational institutions can become "smart" and interconnected, with resultant enhancement or improvements in the way we live and learn.which promises to substantially enhance or change the ways in which we live, play, work, and learn ${ }^{80}$. There have also been great advances in wearable computing and electronic technologies that have made possible the "Internet of Me" ${ }^{81}$ Such technologies and products include smart watches (Apple Watch), smart clothes (Fitbit, Nike+, FuelBand), smart glasses (Google glass, Oculus Rift), head mounted cameras (GoPro), etc. These wearable technologies and the IoT hold much potential for and have many possible applications in education and training ${ }^{81-84}$. Wearables can provide real-world contexts and enable learning to occur anywhere and anytime. Companies are developing apps for wearable devices that allow students to demonstrate their learning. Devices such as the Oculus Rift can be used to provide virtual reality systems. The use of IoT in educational environments has given rise to terms such as "hypersituation" to explain the potential of IoT in learning situations. Hypersituating is the ability to amplify knowledge based on the user's location. In other words, students that carry connected devices with them can benefit by having other interdisciplinary information relayed to them from their surroundings. For instance, a student in a city can explore his/her environment via the architecture, politics/history, or biology depending on how the surroundings are equipped. IoT can also create crowd sourced contributions and observations from the community via networked objects. ${ }^{85}$ Cisco Systems has laid out a vision for networked technologies that incorporate people, processes, and data $^{83}$. For instruction, IoT in higher education takes the form of blended learning models that integrate personalized materials and formative assessment technologies that deliver instant feedback. Therefore, students will have the ability to monitor their own environment and collect real-time data for further study. Like hypersituating, Cisco Systems also envisions a context-aware environment, where objects can communicate with students and vice versa to create relevant, interactive learning experiences.

\section{g. Cloud computing}

Cloud computing is a distributed computing paradigm that enables access to virtual resources including computers, networks, storage, development platforms or applications ${ }^{86}$. These resources can be unilaterally requested, provisioned and configured by the user with a minimal interaction with the cloud provider (such as Google, Amazon, Microsoft). Furthermore, resources can be rapidly scaled up and down to meet the user's needs, thus creating the illusion of infinite resources available at any time. In education, cloud computing can provide e-learning services, especially in scenarios where these services are computer-intensive (e.g., virtual worlds, simulations, video streaming), or for MOOCS. In 
addition, the cloud can provide students and teachers with tools to deploy computing resources on-demand for lectures and labs according to their learning needs. For instance, teachers can create virtual computers (Virtual Machines or VMs) on demand with pre-installed software to deploy computing laboratories rapidly (e.g., reference 87). Cloud computing can be used to offer collaboration tools or data storage and host institutional Virtual Learning Environments. ${ }^{88}$ Other possible applications could be new scenarios where advanced online tools and collaboration can be combined to form new innovations in education. Adaptive learning techniques for use with MOOCs can be implemented easily on cloud systems. There are two good reviews of cloud computing in education which are highly recommended. ${ }^{89,90}$

\section{DISCUSSION AND CONCLUSIONS}

We all live in an information society and the rate of change in technology is breathtaking. Some fundamental question to ponder are, (1) how can technology-supported learning help to move beyond mere content delivery and truly enhance science, technology, engineering and mathematics (STEM) education and help students develop a broad mix of skills? (2)Can technology aided teaching spark thinking and creativity, increase student engagement, and build collaboration? (3) Can technology make STEM teaching and learning more effective, more relevant, and more accessible and more individual? And a final question is a major issue raised in the Introduction, namely how can large number of students be educated effectively? In this paper, we have tried to give an insight into how some of these questions can be answered using technological tools available to us at present.

The U.S. Department of Education's National Education Technology Plan (NETP) presents a vision for learning powered by technology ${ }^{91}$. The NETP discusses how technology can support individualized learning to address students personal needs and interests as well as provide access to learning opportunities anywhere and for life long learning. The plan describes how technology-based assessments can be embedded into learning activities to support just-in-time assistance, measure important student competencies, and provide feedback to provide for continuous improvement efforts across the entire education system. The NETP also suggests a new role for teachers in that rather than being individuals, they shift to connected teaching via networks which form professional communities. These will support student learning and will incorporate data and insights from information provided by technology such as IoT, cloud computing, etc. The NETP also envisions a learning infrastructure that provides access to people and resources at all levels of the education system and a role for technology in enabling the redesign and transformation of education in ways that increase efficiencies.

Even though we have provided some examples of the use of information technology in the service of teaching here, much remains to be done - this calls for imagination, creativity and thinking out of the box. It calls for unique applications of present (and future) technology. However a fundamental issue is whether technology can overcome poor teaching ability. A recent commentary offers a bleak view ${ }^{92}$. According to Kentaro Toyoma, the writer of this commentary, "While technology helps education where it's already doing well, technology does little for mediocre educational systems; and in dysfunctional schools, it can cause outright harm". According to the commentator, since technology is a tool, its effect depends upon well-intentioned capable people and good outcomes are never guaranteed. In fact in his recent book, ${ }^{93}$ Toyoma argues that even in an age of amazing technology, social progress depends on human changes that gadgets can't deliver. In the case of education this comes down to student motivation. In this age of information, getting information/knowledge is easy; however the motivation to learn and master this information is the bottleneck. We could have the best possible educational technology, however the success of this technology depends upon having a motivated and interested audience. Therefore, the key is the individual student. We should use technology to augment and supplement learning in new and different ways and to directly engage the student. The rest is up to the learner! 


\section{REFERENCES}

[1] Uvalic-Trubic, S. UNESCO global forum on rankings and accountability in higher education, www.col.org/resources/speeches/2011 presentations/Pages/2011-05-16.aspx , 2011.

[2] Maslen, G. "Worldwide student numbers forecast to double by 2025 ", University World News, Issue \# 202, http://www.universityworldnews.com/article.php?story=20120216105739999, 2012.

[3] The World Bank, <wdl.worldbank.org/table/2.11>, 2015.

[4] See for example, Alberts, B., "Restoring science to science education", Issues in Science and Technology, Volume XXV, issue 4, Summer 2009. http://issues.org/25-4/alberts-2/

[5] Felder, R.M., "Reading the second tier: learning and teaching styles in college science teaching", J.College Science Teach., 23, 286-290, 1993.

[6] Kuhn, T. "The structure of scientific revolutions: postscript 1969", in The Philosophy of Science, eds. R.Boyd, P.Casper, J.D.Trout, MIT Press, Cambridge, MA., Pages 174-210, 1991.

[7] Seymour,E., Hewitt, N.M., "Talking about leaving: why undergraduates leave the sciences", Westview press, Boulder, CO., 1997.

[8] Mlot, C., "Is science talent squandered?" Science News, 151, www.sciencenews.org/sn arc97/5 31 97/bob1.htm , 1997.

[9] Reddish, E.F., Steinberg, R. “Teaching Physics: Figuring out what works”, Physics Today, 52,24-30,1999.

[10] Wieman, C., Perkins, K., "Transforming physics education", Physics Today, 58,36-41, 2005.

[11] McDermott, L., "Oersted Medal Lecture 2001: Physics education research - the key to student learning", Am J Phys, 69,1127-1137, 2001.

[12] See the Physics Education Research website: www.perusersguide.org

[13] National Research Council,"Adapting to a changing world - challenges and opportunities in undergraduate physics education" The National Academies Press, Washington DC, 2013.

[14] Mcdermott, L., Redish, EF, "Resource letter PER-1: Physics education research", Am J Phys., 67, 755-767, 1999

[15] Meltzer DE, Thornton RK, "Resource letter ALIP-1: Active learning instructions in physics", Am J Phys., 80, 478496, 2012

[16] Molnar, A., "Computers in education: a brief history", http://thejournal.com/articles/1997/06/01/computers-ineducation-a-brief-history.aspx, 1997.

[17] Aguilar, L., Walten, G., Wieman, C. "Psychological insights for improved physics teaching", Physics Today, 67, 43-49, 2014.

[18] Bryson, S. "Virtual reality in scientific visualization", Comm. ACM, 99,62-71, 1996.

[19] Milrad, M. "Using construction kits, modeling tools and system dynamics simulations to support collaborative discovery learning". Educational Technology \& Society, 5 (4), 76-87, 2002.

[20] Sampson, D. G., Spector, J. M., Devedzic, V., \& Kinshuk. "Remarks on the variety and significance of advanced learning technologies". Educational Technology \& Society, 7 (2), 14-18, 2004.

[21] Salzman, M. C., Dede, C., Loftin, R. B., \& Chen, J. "A model for understanding how virtual reality aids complex conceptual learning”. Presence, 8 (3), 293-316, 1999.

[22] Gordin, D. N., \& Pea, R. D.,’Prospects for scientific visualization as an educational technology”. The Journal of the Learning Sciences, 4 (3), 249-279, 1995.

[23] Bowman, D. A., Hodges, L. F., Allison, D., \& Wineman, J. The educational value of an informationrich virtual environment (GVU Technical Report; GIT-GVU-98-05). Georgia Institute of Technology, 1998.

[24] Chee, Y. "Virtual reality in education: Rooting learning in experience". Proc.Int. Symp. Virtual Education, Busan, South Korea, pp. 43-54 http://yamsanchee.myplace.nie.edu.sg/Publications/2001/ISVE2001 Invited.pdf, 2001.

[25] Dede, C., Salzman, M.C., \& Bowen Loftin, R., "MaxwellWorld: learning complex scientific concepts via immersion in virtual reality", Proc. ICLS '96 Proceedings of the 1996 international conference on Learning sciences, Pages 22-29, 1996.

[26] Pantelidis,V. S. "Virtual reality and education: Information sources; a bibliography"http://vr.coe.ecu.edu/vpbib.html

[27] Pantelidis, V.S., "Reasons to use virtual reality in education and training courses and a model to determine when to use virtual reality", Themes in Sci. and Tech. Ed., 2, 59-70,2009.

[28] Hanson, K., \& Shelton, B. E. "Design and Development of Virtual Reality: Analysis of Challenges Faced by Educators", Educational Technology \& Society, 11, 118-131, 2008.

[29] Chen, C. J.,:The design, development and evaluation of a virtual reality based learning environment",Australasian Journal of Educational Technology, 22(1), 39-63, 2006. 
[30] Barber, M., and Njus, D. Clicker evolution: seeking intelligent design. CBE—Life Sci. Educ. 6, 1-8., 2007.

[31] See www.edsurge.com/n/check-this-out-a-comparison-of-audience-response-systems ; accessed June 7, 2015.

[32] Watkins E. and Sabella, M., , "Examining the effectiveness of clickers in promoting learning by tracking the evolution of student responses." Proceedings of the 2008 Physics Education Research Conference, Edmonton, Alberta, CA, 1064, 223-226,2008.

[33] Stull, J.C., Majerich, D.M., Smythe, A.C., Varnum, S.J., Ducette, J.P. \& Gilles, T. "Using clickers in a university physics course to improve student achievement",http: // www.aps.org/units/fed/newsletters/spring2011/stull.cfm, 2011.

[34] Perkins, K.K., and Turpen, C. "Student perspectives on using clickers in upper division physics courses" Physics Education Research Conference, Ann Arbor, MI., pages 225-228. http://www.cwsei.ubc.ca/SEI research/files/Physics/Perkins StudentPerpectivesOnUsingClickersL.pdf, 2009.

[35] Beatty, I. D., Gerace, W. J., Leonar, W. J., and Dufresne, R. J. "Designing effective questions for classroom response system teaching". Am. J. Phys. 74(1), 31-39, 2006.

[36] Poulis, J., Massen, C., Robens, E., and Gilbert, M. "Physics lecturing with audience paced feedback". Am. J. Phys. 66(5), 439-441, 1998.

[37] Burnstein, R. A., and Lederman, L. M. "Using wireless keypads in lecture classes". Phys. Teach. 39, 8-11, 2001.

[38] Li, P. "Creating and evaluating a new clicker methodology", Ph.D. thesis, Department of Physics, Ohio State University, Columbus, OH. 2007.

[39] See http://cft.vanderbilt.edu/docs/classroom-response-system-clickers-bibliography/

[40] Ohio State University. "Students Who Use 'Clickers' Score Better On Physics Tests." Science Daily, 18 July 2008. www.sciencedaily.com/releases/2008/07/080717092033.htm, 2008.

[41] See for example, University of Colorado Science Education Initiative, "Clicker resource guide", http://www.cwsei.ubc.ca/resources/files/Clickers_Final_Version_04_08.pdf, accessed June 07,2015.

[42] Caldwell, J.E.," Clickers in the Large Classroom: Current Research and Best-Practice Tips", CBE—Life Sciences Education, 6,9-20,2007.

[43] Lage,M.J., Platt, G.J., and Treglia., M., "Inverting the classroom: A gateway to creating an inclusive learning environment". Journal Econ. Education, 31,30-43, 2000.

[44] See: http://cft.vanderbilt.edu/guides-sub-pages/flipping-the-classroom/

[45] http://www.thedailyriff.com/articles/how-the-flipped-classroom-is-radically-transforming-learning-536.php; see also Tucker, B. , “The flipped classroom", Education Next, pages 82-83, 2012.

[46] The survey results are summarized in: http://www.facultyfocus.com/articles/edtech-news-and-trends/surveyconfirms-growth-of-the-flipped-classroom/, 2014.

[47] Deslauriers, L., Schelew, E., \& Wieman, C. "Improved learning in a large enrollment physics class", Science, 332,862-864, 2011.

[48] Bishop,J.L. \& Verleger, M., "The flipped classroom: a survey of the research", $120^{\text {th }}$ ASEE annual conference and exposition, Atlanta, GA., Paper ID \#6219, http://www.asee.org/public/conferences/20/papers/6219/view, 2013.

[49] See: http://researchnetwork.pearson.com/educator-effectiveness/resources/flipped-learning-resources , accessed June 7, 2015.

[50] http://en.wikipedia.org/wiki/M-learning

[51] Frohberg, D., Goth, C., Schwabe, G. "Mobile learning projects - a critical analysis of the state of the art". Journal of Computer Assisted Learning 25, 307-331,2009.

[52] Sharples, M., Arnedillo-Sánchez, I., Milrad, M., Giasemi, V. "Mobile learning,small devices, big issues." In: Ludvigsen, S., Balacheff, N., de Jong, T., Lazonder,A., Barnes, S. (Eds.), Technology-Enhanced Learning: Principles and Products., Springer, Dordrecht, pp. 1-20. 2008.

[53] Valdivia, R., Nussbaum, M., "Using multiple choice questions as a pedagogic model for face-to-face CSCL". Computer Applications in Engineering Education 17, 89-99, 2009.

[54] Yin, C., Ogata, H., Yano, Y., "Participatory simulation framework to support learning computer science. International Journal of Mobile Learning and Organization",1, 288-304, 2007.

[55]Looi, C., Chen, W. "Community-based individual knowledge construction in the classroom: a process-oriented account". Journal of Computer Assisted Learning, 1-12, 2010.

[56] Educause Center for Applied Research. "ECAR study of undergraduate students and information technology". Louisville, CO. http://net.educause.edu/ir/library/pdf/ERS1208/ERS1208.pdf 2012.

[57] Gikas, J and Grant, M.M. "Mobile computing devices in higher education: Student perspectives onlearning with cellphones, smartphones \& social media" Internet and Higher Education 19,18-26, 2013. 
[58]Liu, T., Peng, H., Wu, W., \& Lin, M. "The effects of mobile natural-science learning based on the 5E learning cycle: A case study". Educational Technology \& Society, 12, 344-358, 2009.

[59] Sharples, M., Taylor, J., \& Vavoula, G. "A theory of learning for the mobile age", In R. Andrews \& C. Haythornthwaite (Eds.), The Sage handbook of elearning research. Sage, London, Pages 221-247, 2007.

[60] Keengwe, J and Maxfield, M.B. "Advancing Higher Education with Mobile Learning Technologies: Cases, Trends, and Inquiry-Based Methods", Information Science Reference, Hershey,PA., 2015.

[61] Kim, Y., Jeong, S.JI, Y., Lee, S., Kwon, K.H., Jeon, J.W.”Smartphone response system using twitter to enable effective interaction and improve engagement in large classrooms", IEEE Trans. Education, 58, 98-103,2015.

[62] Alvarez, C., Alarcon, R., \& Nussbaum, M. "Implementing collaborative learning activities in the classroom supported by one-to-one mobile computing: A design-based process" J. Systems Software, 84,1961-1976, 2011.

[63] Hwang, G-J and Tsai C-C.,, "Research Trends in Mobile and Ubiquitous Learning: A Review ofPublications in Selected Journals from 2001 to 2010," Brit. J. of Ed. Technology, 42,E65-E70,2011.

[64] Wu, W-H,Wu,Y-C.J.,Chen, C-Y., Kao, H-K., Lin, C., \& Huang,C.,"Review of Trends from Mobile Learning Studies: A Meta-Analysis," Computers \& Education, 59,817-827, 2012.

[65] Kim, P. Massive Open Online Courses: The MOOC revolution, Routledge, NY, 2014.

[66] Krause, S.D., Lowe C., Invasion of the MOOCS: the promise and perils of MOOCS, Parlor Press, Anderson, SC, 2014.

[67] Haber, J., MOOCS, MIT Press, Cambridge, MA., 2014.

[68] Carr, N. The crisis in higher education. MIT Tech Rev.,http://www.technologyreview.com/featuredstory/429376/thecrisis-in-higher-education/, 2012.

[69] Rodriguez, C. O. MOOCs and the AI-Stanford like courses: Two successful and distinct course formats for massive open online courses. Eur.. J. of Open, Distance \& E-Learning. http://www.eric.ed.gov/PDFS/EJ982976.pdf, 2012.

[70] Kolowich, S. The minds behind the MOOCs. The professors who make the MOOCs. The Chronicle of Higher Education. http://chronicle.com/article/The-Professors-Behind-the-MOOC/137905/\#id=overview ,2013.

[71] http://www.stanforddaily.com/2013/06/04/moocs-face-challenges-in-teaching-humanities/, 2013.

[72] https://www.google.com/cse?cx=partner-pub-3252929032242305:3580054474\&ie=UTF$8 \& q=0 p t i c s \& s a=$ Search\&ref=www.mooc-list.com/\#gsc.tab=0\&gsc. $q=$ optics\&gsc.page $=1$; accessed June 08,2015 .

[73] www.edsurge.com/n/2014-12-26-moocs-in-2014-breaking-down-the-numbers; accessed June 08, 2015.

[74] Jordan, K. https://www.insidehighered.com/news/2013/05/10/new-study-low-mooc-completion-rates, accessed June 08,2015 .

[75] http://www.katyjordan.com/MOOCproject.html, accessed June 08,2010.

[76] Friedman,T., "Revolution hits the universities", New York Times, January 26, 2013

[77] Christensen,G,Steinmetz,A.,Alcorn,Bennett,A.,Woods,D.,Emanuel,E.J., “The MOOC Phenomenon: Who Takes Massive Open Online Courses and Why?" http://papers.ssrn.com/sol3/papers.cfm?abstract id=2350964, 2015.

[78] Levine,A.,"MOOCs,history and context" InsideHigherEd. www.insidehighered.com/views/2013/04/29/essaynature-change-american-higher-education, 2013.

[79] http://en.wikipedia.org/wiki/IPv6

[80]Feki,M.A.,Kawsar, F.,Boussard, M.and Trappeniers, L. "The internet of things: the next technological revolution", Computer, 42, 24-25, 2013.

[81] Spicer, A. and Cederström, C., "You've heard of the Internet of Things, now behold the Internet of Me," http://theconversation.com/youve-heard-of-the-internet-of-things-now-behold-the-internet-of-me-36379, 2015.

[82] Lee,V.R., "Learning Technologies and the Body: Integration and Implementation in Formal and Informal Learning Environments" Routledge,NY, 2015.

[83] Selinger,M., Sepulveda,A.,and Buchan,J. "Education and the Internet of Everything: How ubiquitous connectedness can help transform pedagogy," http://www.cisco.com/web/strategy/docs/education/education_internet.pdf, 2013.

[84] Johnson, L., Adams Becker, S., Estrada, V., and A. Freeman, "NMC Horizon Report: 2015 Higher Education Edition". The New Media Consortium Austin, TX: http://www.nmc.org/publication/nmc-horizon-report-2015higher-education-edition/, 2015.

[85] http://www.educause.edu/ero/article/ubiquitous-and-thensome?utm_source=Informz\&utm_medium=Email+marketing\&utm_campaign=EDUCAUSE;accessedJune 08,2015.

[86] Mell, P., \& Grance, T. "The NIST definition of cloud computing". Technical Report 15, National Institute of Standards and Technology, Information Technology Laboratory. 2009. 
[87]Chine, K. "Learning math and statistics on the cloud, towards an ec2-based google docs-like Portal for Teaching/Learning Collaboratively with R and scilab". In Proc. International Conference on Advanced Learning Technologies (ICALT '10), pp. 752-753, 2010.

[88] Sclater, N. "Cloud computing in education". Technical Report, UNESCO Institute for Information Technologies in Education. 2010.

[89]Fasihuddin, H., Skinner, G., \& Athauda, R. "A holistic review of cloud-based e-learning system". Proc. IEEE International Conference on Teaching, Assessment and Learning for Engineering (TALE '12) ,pp. 6-11, 2012.

[90] Gonzalez-martinez, J.A., Bote-Lorenzo, M.L., Gomez-Sanchez, E. And Cano-Parra, R., "Cloud computing and education: A state of the art survey", Computers and Education, 80,132-151, 2015.

[91] Office of Educational Technology, "Transforming American education. Learning by technology", U.S. Department of Education, Washington D.C., http://tech.ed.gov/wp-content/uploads/2013/10/netp2010.pdf, 2010.

[92] Toyama,K. "Why technology will never fix education", http://chronicle.com/article/Why-Technology-Will-NeverFix/230185/?cid=gn\&utm source=gn\&utm medium=en, 2015.

[93] Toyoma, K., "Geek Heresy: Rescuing Social Change from the Cult of Technology”, Public Affairs, NY, 2015. 